\title{
Elitismo y antiintelectualismo en la España del primer tercio del siglo XX
}

Paul Aubert *

"Señoras y señores, no soy ningún tonto.» Las circunstancias históricas llegarán a poner esta profesión de fe, que Paul Valéry atribuía a su apócrifo, Monsieur Teste, en boca de intelectuales tales como Ortega y Unamuno - y no sólo a modo de provocación o de revulsivo - cuando se vieron obligados a tal autodefinición no exenta de osadía por lo que interpretaron como ramplonería ambiente o imbecilidad oficial.

¿Cómo explicar pues este rasgo característico de la historia de la España contemporánea: la participación masiva de los intelectuales en la vida política, si no la reivindicación del monopolio de la inteligencia, la pretensión de ostentar el monopolio del discurso social? ¿Qué pueden los intelectuales? ¿Qué clase de magisterio, qué tipo de poder son los suyos para que les tema el poder político y para que lleguen a odiarles varios grupos de la sociedad?

¿Cómo se resuelven pues estos problemas de la identidad, de la ubicación y del papel del intelectual en la crisis de la sociedad burguesa y del régimen, de la Restauración?

\section{LLAMAMIENTO A LOS INTELECTUALES Y A LOS MEJORES}

En los momentos críticos, la burguesía y sus hipotéticos intelectuales orgánicos, pero también quienes desde los márgenes del reformismo aspiran a racionalizar la vida política, dan reiteradamente el grito, buscando la redención en las academias y los paraninfos en busca de los mejores:

\footnotetext{
* Universidad de Aix Marsella-Casa de Velázquez.
} 
"Pero, ¿dónde están los intelectuales?» La inteligencia es considerada como un elemento del progreso social. Por consiguiente, la ausencia o la inhibición de los que hacen profesión de ésta es sinónimo de decadencia y de catástrofe moral.

"Todo individuo tiene la obligación de intervenir en política en defensa de los intereses de la clase oprimida, que son los suyos propios; pero los intelectuales con mayor razón"'. De hecho, la sociedad burguesa le reconoce alguna función al intelectual, aunque comprueba a menudo que estos apóstoles de la cultura, denunciadores de la injusticia, dispuestos a oponer siempre la razón colectiva a la razón de Estado se han acercado a la clase obrera. Algunos observadores, a menudo comprometidos - por ejemplo, Luis de Zulueta en $1919^{2}$, o Quintiliano Saldaña en $1930^{3}$ - no vacilan en describirles como los protagonistas de una verdadera guerra de clases. Otros ven, en esta manifestación de solidaridad con los trabajadores, una traición a su clase burguesa de origen.

"Los intelectuales, por su propia voluntad, se han abrazado a los proletarios. Acaso (...) la causa de este rumbo emprendido por los intelectuales haya sido el poco aprecio que encontraran en clases aristocráticas" ${ }^{4}$. Tal explicación de una rebeldía por despecho es elemental pero no carece de fundamento. Es cierto que el régimen de la Restauración ha favorecido la aparición de una clase de "profesionales", de trabajadores intelectuales, funcionarios, abogados, periodistas, que ha crecido de modo independiente y que constituye una elite relativamente numerosa ya que no puede ser asimilada por el poder, como en el siglo anterior. Al monopolizar los medios de comunicación, elabora un nuevo discurso político de oposición que aspira a ser nacional y llegará a ser republicano.

\section{a) Formas del compromiso de los intelectuales}

Desde el principio la misma noción de cintelectual» es polémica. El intelectual es hijo de las circunstancias frente a las cuales se sitúa y se autodefine. Podemos acercarnos a esta noción de «intelectual» según dos modalidades:

' Nistal, M., "El apoliticismo estudiantil», Nosotros. Madrid 25 de abril de 1931, núm. 39, pág. 9 .

"La guerra de clases", El Mercantil Valenciano, 7 de noviembre de 1919.

3 "Actualidad política. Aquí no ha pasado nada", Política, 1 de diciembre de 1930, núms. 11-12.

4 "Proletarios e intelectuales», Nosotros, Madrid 25 de abril de 1931, núm. 39, pág. 9. 
- Una funcional, sociológica, para describir al trabajador intelectual vinculado de algún modo, según el momento, a las necesidades de la formación social. Éste desempeña un papel de transmisión y de reproducción del saber práctico más que producción ideológica.

- Otra coyuntural, histórica, para comprobar la emergencia de un grupo que se autodefine como grupo de los intelectuales frente a algún acontecimiento para luchar contra la razón de Estado en nombre de la razón universal. En este sentido la campaña para la revisión del proceso de Montjuich es una versión hispana del affaire Dreyfus, que había permitido ya a la intelectualidad española tomar partido durante el militarismo o el antisemitismo y por el derecho que simboliza Zola.

Estos intelectuales se formaron una conciencia crítica frente a los acontecimientos nacionales (del proceso de Montjuich al caso Ferrer) e internacionales (del "affaire Dreyfus» a la Revolución rusa). Por lo tanto, estos intelectuales autodefinidos como tales en el comentario del acontecimiento son de alguna manera, en el ámbito de la comunicación social, hijos de las circunstancias en cuanto pudieron valerse con fines políticos de una fama adquirida en el dominio literario o científico. Ser un intelectual no es un oficio, sino una actitud que responde o se adecúa a una situación.

Es preciso realizar a la vez un estudio diacrónico, para tener en cuenta el hecho de que son hombres de distinta madurez y que su evolución personal les hace ver los mismos problemas desde diversas perspectivas, y sincrónico para poder medir las interacciones e influencias recíprocas de los que son objeto a lo largo de las discusiones o de las polémicas.

Proclamar su calidad de intelectual participa también de un chantaje consciente. Cuando tiene que declarar delante del jurado Zola se define como un escritor famoso, dispuesto a enarbolar todo su prestigio literario para que triunfe lo que concibe como la verdad, asumiendo el riesgo de ver alterados tanto la producción de su obra como el curso de su propia existencia. No vacila, y echa todos sus libros en el plato de la justicia.

Sin embargo, España representa un caso tal vez único, al menos lo suficientemente singular como para ser analizado como tal, el de un país en que los intelectuales no se contentan con el comentario de la vida política "sin el contrapeso de los actos reales" ${ }^{5}$. Estos asumen un com-

\footnotetext{
5 "Le métier des intellectuels est de remuer toutes choses sous leurs signes, noms ou symboles, sans le contrepoids des actes réels. II en résulte que leurs propos sont étonnants, leur politique dangereuse, leurs plaisirs superficiels. Ce sont des excitants sociaux avec les avantages et les périls des excitants en général", ValéRY, Paul, Rumbs: Tel Quel. París, Gallimard, Bibliothèque de la Pléiade, 1960, t. II, pág. 619 (Iª edición, París, Gallimard, 1926, pág. 125).
} 
promiso político, hasta ser omnipresentes en la vida política y social y constituir la principal oposición al régimen de la Restauración y verse confundidos, e identificados con el régimen de la Segunda República a cuyo advenimiento y funcionamiento han contribuido, asumiendo, por consiguiente, los éxitos y los fracasos de éste.

España constituye pues un caso atípico en la Europa de los siglos XIX $y x x$, en la que se ha constituido lo que Manheim llamó una cintelligentsia laica" " ${ }^{6}$, en la medida en que los intelectuales forman un grupo minoritario aislado que va cobrando coherencia dentro de una minoría ilustrada. Se trata de una especificidad tan estructural como coyuntural de un país donde el Estado puede negar u ocultar los conflictos o los problemas ${ }^{7}$ pero no sabe resolverlos. En Francia, por ejemplo, el Affaire Dreyfus se resuelve, a pesar de todo, dentro del régimen. En España tales mecanismos no funcionan. Protestar contra las irregularidades de unos procesos es un rito que termina siempre por cuestionar la misma índole, la misma legitimidad del Poder. Ciertos intelectuales han llegado a pensar que todo estaba por hacer para que funcionara un Estado de derecho y por consiguiente creyeron que lo podían todo. No sólo se trató de detener la decadencia del país o de regenerarlo; se quiso reformar las formas y las normas mismas del poder, y luego apoderarse de éste al comprobar que no se podía jugar con él.

Trataremos de entender cómo este sentimiento de disconformidad, de rebeldía, que experimentaron los intelectuales, pudo estructurarse hasta el punto de llegar a ser una amenaza para el poder a lo largo de la crisis del régimen, de la Restauración (de esta creciente politización de la vida española que observaba Gramsci desde su cárcel mussoliniana), y de llegar a ser el mismo poder, en abril de 1931.

¿Cómo concebían su propio papel? De hecho, los intelectuales se encuentran frente al viejo dilema de la reflexión y de la acción. Aunque para ellos actuar consiste sobre todo en hablar y escribir. Están, por esencia, opuestos al poder al comprobar el desajuste que existe entre las normas y su realización práctica. Se otorgan, sin embargo, como Araquistain ${ }^{8} 0$ Fernando de los Ríos ${ }^{9}$, un papel regulador, de intermediario entre la clase

\footnotetext{
${ }^{6}$ ManheIM, K., Mensch und Gesellschaft im Zeitalter des Umbaus. Leyde, 1935; Essays on the Sociology of Culture. Londres, 1956

7 Machado, Antonio, El tabú solución de todo problema. Prosas completas, ed. de O. Macú. Madrid, Espasa Calpe, 1989, pág. 1631.

" "Agitación obrera y crisis del parlamentarismo", El Liberal, 27 de mayo de 1912.

${ }^{9}$ Rios, Fernando de los, "La exaltación del hombre como valor fundamental de la historia: Liberalismo y socialismo", Conferencia pronunciada en el Ateneo de Madrid, el 14 de enero de 1912; Escritos sobre Democracia y Socialismo, ed. de Virgilio Zapatero. Madrid, Taurus, 1974, pág. 61
} 
obrera y la burguesía, siendo atípica la reacción nihilista de un Rodríguez de la Peña ${ }^{10}$ o de un Baroja ${ }^{11}$ que pretenden destruir únicamente los

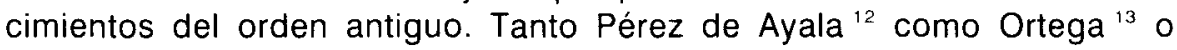
Araquistain ${ }^{14}$ insisten reiteradamente en la necesidad para el intelectual de contribuir a la formación de una conciencia colectiva militando en una vanguardia consciente.

Desde las críticas argumentadas, hasta los insultos en prosa y en verso que Unamuno lanzaba a los gobernantes desde la "proscripción" (como gustaba de decir), no dejan de manifestarse públicamente. Quieren denunciar las injusticias, y luego hacer funcionar el poder. No tienen un programa preciso y se mueven entre el positivismo regeneracionista y el liberalismo social. No obstante, sus campañas contra la represión, contra la Ley de Jurisdicciones, contra el Gabinete Maura y la guerra de Marruecos, luego a favor de la amnistía, aunque el sentido de sus reivindicaciones cambia, llegan a cuestionar, más allá de la persona del monarca o de la política del Gobierno, la esencia misma del régimen.

Una tipología de este compromiso público de los intelectuales que no separa el análisis de las mentalidades del de sus lugares y de sus medios de producción - firmas de manifiestos, manifestaciones, mitines, conferencias, discursos, colaboraciones periodísticas - muestra según qué lógica éstos se autodefinen en el comentario del acontecimiento.

Los manifiestos pertenecen a un género didáctico intermediario. Son textos escritos para ser oídos en público: «Pero ¿qué conciencia pública puede haber sobre el problema de Marruecos, si nosotros mismos los intelectuales, no sabemos nada?, interrogaba Ramiro de Maeztu en 1910" ${ }^{15}$, negando casi la realidad de un problema del que no se había enterado, mientras Unamuno definía así, con tan poca modestia, su función de intelectual: "Quizá llegaré a comenzar a tomar conciencia del problema y pueda ayudar a los demás a tomarla» ${ }^{16}$.

Publicar un manifiesto es reivindicar esta clarividencia, este orgullo de haber entendido el primero el sentido de los acontecimientos; y de dis-

10 "La política y los intelectuales", El Radical, 3 de enero de 1912.

11 «El intelectual va demoliendo la casa vieja e incómoda: el obrero va poniendo los cimientos de la casa del porvenir. La misión de la intelectualidad no es otra: destruir" (Nuevo Tablado de Arlequín, 1917, pág. 84).

12 «Política y toros", prólogo a la primera edición, OC. Madrid, Aguilar, 1963, t. III, pág. 838

${ }^{13}$ Vid. por ejemplo, "Vieja y nueva política", OC, t. X.

${ }_{14}$ España en el crisol. Madrid 1920, pág. 53.

${ }^{15}$ Nuevo Mundo, 11 de julio de 1913.

${ }^{16}$ Ibidem. 
frutar del monopolio del uso de la palabra autorizada, que marca las normas y los límites. Es otorgarse el privilegio de decir lo bueno y lo malo, las normas del poder y los límites entre las clases sociales, de decidir entre las realidades y las ficciones, contribuyendo al mismo tiempo a la formación de la oponión. Es ejercer -como dice Pierre Bourdieu-, en una lucha por el monopolio de la representación legítima del mundo social, este privilegio de hacer existir en las conciencias y en la realidad las divisiones del mundo social.

\section{- Orador y periodista}

De hecho, muchos intelectuales disponen de una crónica y de una tribuna. Hablan en los mitines o en el Ateneo, escriben en la prensa. Son periodistas transformados por su sola colaboración en intelectuales, o periodistas que se toman, a causa de ésta, por unos intelectuales. El recuerdo de estas relaciones ambiguas - puesto que es tanto el periódico que hace al intelectual como el intelectual que hace el periódico- no debe hacer olvidar que encontramos su firma en casi todos los diarios y revistas españoles y algunos americanos (argentinos en particular). Disponen de unos órganos más específicos Los Lunes de El Imparcial, España, El Sol, Crisol, Leviatán. Comprobaremos que esta producción ideológica es impresionante y cada vez mayor, y que los intelectuales españoles redactaron su obra exclusivamente a base de colaboraciones periodísticas.

Recordaremos, por otra parte, la importancia simbólica de las conferencias de Maeztu, de Unamuno, de Ortega, de Albornoz, de Domingo, de Ovejero, durante la Restauración stricto sensu, de Saínz Rodríguez, de Jiménez de Asúa durante la dictadura de Primo de Rivera.

El intelectual se define y se autodefinen en el comentario del acontecimiento teniendo al mismo tiempo la necesidad o la ilusión de hablar públicamente en nombre del pueblo legitimador. En esto radica la ambigüedad de su postura: hablar al pueblo en nombre del pueblo, porque primero era preciso saber lo que era el pueblo y qué lugar le estaba reservado en las luchas futuras.

Pero en esta lenta trayectoria hacia el poder tuvieron los intelectuales que adecuar su afán de reforma social a las formas de la vida política. Evidentemente el compromiso político tenía formas más corrientes. Al final de la primera década la adhesión de muchos de ellos a los partidos políticos era un hecho importante. 
Se configuran durante la primera década del siglo, después del retraimiento de Maura y del fracaso de Canalejas varias estrategias y se constituyen nuevas formaciones políticas de oposición al régimen que atraen a los intelectuales. Conjunción republicano-socialista (1909), Partido Radical (esbozado en 1908, aunque creado efectivamente en 1910), Partido Reformista (1913), antes de que el Partido Socialista modifique su línea obrerista y acoja de nuevo a los intelectuales (1912-1915).

Sin embargo, la filiación política de éstos evoluciona, al menos hasta la Primera Guerra mundial. De tal manera que el que había contribuido a formular un proyecto reformista llega a ser el autor, cinco años más tarde de unas bases socialistas (Luzuriaga en el dominio de la instrucción pública); mientras que la vehemencia de tal orador radical encuentra una formulación socialista razonada (es el caso de Andrés Ovejero). Zulueta atraído por el Partido Radical, en 1908, pasa a la Conjunción republicanosocialista en 1910 y al reformismo en 1914, aunque haya tenido -como Marcelino Domingo - relaciones con los anarquistas en 1906 en el seno del Ateneo Enciclopédico Popular de Barcelona (del que llegó a ser presidente) fundado por ex-miembros de "La Escuela Moderna». Un contexto tan movedizo no contribuye, ni mucho menos, a la nitidez del análisis. Tanto más cuanto que algunos manifiestos logran crear corrientes transversales, como cuando la constitución de la Liga de Educación Política de Ortega dentro del Partido Reformista, en 1913, que cierra la experiencia de acercamiento del joven catedrático al socialismo español. El manifiesto de la Liga reúne las firmas de muchos miembros de la Escuela Nueva, creada dos años antes por Manuel Núñez de Arenas, con el fin de superar el obrerismo de la dirección del PSOE. «Sabemos que los objetivos de las dos entidades eran distintos, e incluso que tenían concepciones opuestas. La Liga tenía una visión elitista de su misión cuando la Escuela Nueva pretendía precisamente superar este determinismo político-social y no separaba el hecho cultural de la cuestión social. La doble pertenencia de ciertos intelectuales, indistintamente seducidos por la expresión genérica de un reformismo mediante la educación y la difusión de la cultura (Azaña, Bello, Elorrieta, Luzuriaga, Ortega, Leopoldo Palacios, García Morente, Carande, Ovejero, Pedroso, Odón de Buen, Bernaldo de Quirós, etc.). A pesar del resurgimiento episódico del elitismo de unos y del obrerismo de otros, y de la presencia de los mismos nombres en los intentos políticoculturales de esos años, la participación de los intelectuales en tales empresas (sin olvidar el proyecto de sociedad fabiana, la universidad popular, ni la escuela societaria) revela su fe en una posible modernización de España, y su deseo - más allá del mero rigor doctrinal- de multiplicar 
los lugares "estratégicos". Este deseo participa, sin duda, más de una temática discursiva que de un ideario, pero es el signo evidente de una "clase intelectual" a la búsqueda de soluciones" 17.

El intelectual deja de ser un miembro rebelde o disconforme de la burguesía - cuya expresión última fue a principios de siglo la bohemia (Sawa, Rusiñol, Cavia) como para adquirir una mayor conciencia de grupo y preparar una alternativa política.

Sólo nos consta que la Concentración republicano-socialista y luego los republicanos radicales procuran atraerlos ${ }^{18}$ y que su presencia es numerosa en el IX Congreso del PSOE en 1912 (además de Jaime Vera quien ha recobrado su papel de teórico, hombres más jóvenes, Besteiro, Araquistain, Ovejero (muchos de ellos decepcionados por la demagogia de Lerroux), Fabra Ribas, Pérez Solís, García Cortés y Núñez de Arenas intervinienen en los debates) y mayor aún en el X Congreso de 1915. A partir de entonces su presencia dentro de la oposición al régimen será constante. Desde la Liga de Educación política, en 1913, hasta la Liga Antigermanófila, en 1916, la Unión Democrática Española, en 1918, la "Acción Republicana» y luego la Alianza Republicana, en 1925-1926, la Agrupación al Servicio de la República, en 1930. Desde las filas del reformismo hasta las del socialismo. Y luego en las Constituyentes de 1931 (pero también, si cabe ser exhaustivo, camino de un exilio que en muchos casos no fue más que una huida elegante a partir del verano de 1936).

Frente a la realidad social y política, el intelectual deja de ser también un moralista aislado, un miembro rebelde o disconforme de la burguesía, para adquirir una mayor conciencia de grupo y preparar una alternativa política aunque no resuelve, por ahora, la cuestión de saber si debe militar dentro del reformismo burgués, adherirse al partido del proletariado - corriendo el riesgo de que la clase obrera no reconozca en él un defensor de los intereses populares - o contribuir a la creación de aquel partido de intelectuales siempre en ciernes entre bastidores desde Costa hasta Ortega o Antonio Espina.

Al margen, de los partidos o en su seno, el compromiso de los intelectuales, que perciben y analizan en términos culturales «los males de

\footnotetext{
17 Aubert, Paul, “Madrid, polo de atracción de la intelectualidad a principios de siglo", en A. Bahamonde-L. E. Otero Carvajal (eds.), La sociedad madrileña durante la Restauración. 1876 1931. Madrid, Alfoz-Universidad Complutense, 1989, págs. 101-137.

${ }_{18}$ Vid. por ejemplo, respectivamente: «La concentración republicano-socialista representa la intelectualidad de España", España Nueva, 24 de marzo de 1910; "Los intelectuales deben ser republicanos", El Radical, 13 de diciembre de 1910.
} 
la patria», se expresa inicialmente en términos pedagógicos y llega a coincidir con el de unos educadores que aspiran a reformar el Estado, puesto que el Estado no ha sido capaz de reformar la educación pública. De tal manera que, a lo largo de la Restauración, el discurso pedagógico está dedicado al análisis del fracaso de la escuela y a la glosa del hipotético programa político de un partido de intelectuales ${ }^{19}$. Así es como llegan a confundirse discurso escolar y discurso sobre la escuela, y se transforman por afán pedagógico o meramente demagógico, los proyectos de educación en programas de educación política, desde Costa, hasta Lerroux u Ortega.

\section{b) Corporativismo y modernización del Estado}

«En el orden político lo equivalente a la obra de la generación literaria del 98 está por empezar.» Esta tarea que el joven Azaña asignaba en 1923 a los intelectuales de su generación, se fundamenta en una crítica del regeneracionismo y de las insuficiencias de la protesta del grupo finisecular.

Las primeras manifestaciones regeneracionistas son la expresión de ambiciones de grupos profesionales o estatales que han adquirido mayor importancia y se organizan corporativamente en la bisagra de los dos siglos, con reivindicaciones presupuestarias o escalafonales. De hecho la retórica regeneracionista se fundamenta en reivindicaciones corporativas anteriores y posteriores al desastre de 1898. Estas profesiones que se enfrentan a unas situaciones críticas pretenden luchar contra el estancamiento de la carrera y quieren conseguir mayor dignidad y reconocimiento social. Obviamente el marco económico en que desempeñan su actividad es un factor condicionante importante de la mentalidad de estos grupos.

Estas reivindicaciones regeneracionistas y estas luchas corporativas propia de los notarios y registradores a consecuencia de las campañas de Costa confunden a menudo intereses profesionales e intereses nacionales. Los jueces también están hartos de ver su carrera depender de la benevolencia del cacique aunque temen también las consecuencias de unos proyectos globales de reforma de la administración de la justicia.

\footnotetext{
19 Aubert. P., "Culture et inculture dans l'Espagne de la Restauration. Un nouveau discours sur l'école? (1909-1923)", Clases populares, cultura, educación. Siglos xix y xx. Guereña, J.L. y Tiana, A. eds. Madrid, Casa de Velázquez-UNED, 1990, págs. 467-508.
} 
La lucha de los notarios que pedían - con la Constitución del Bloque Notarial de 1908- una nueva Ley Notarial, una representación profesional consolidada y una vida corporativa más estable, participa de la acción de unos grupos que presionan los centros políticos madrileños. Aunque sin llegar a los procedimientos drásticos preconizados por Costa, refundición o supresión de servicios, despido de personal, reducción de sueldos y pensiones, muchas de estas reivindicaciones abogan por una reforma de la política estatal. Costa acusaba al Estado de generar gastos improductivos y entorpecer las iniciativas individuales ${ }^{20}$. Lo cual explica la poda administrativa que preconiza de nuevo en el programa de la Liga Nacional de Productores ${ }^{21}$.

Sin llegar a tales extremos, las cerca de cuarenta publicaciones de funcionarios que se contabilizan a lo largo de aquella época ${ }^{22}$ expresan reivindicaciones puntuales sin vínculo corporativo duradero. Este rechazo de la intervención política en la vida de los funcionarios parece matizarse a partir de 1919 con la constitución de un nuevo sindicato de profesiones liberales que viene a prolongar la acción de la Asociación de Funcionarios Civiles, constituida a finales del siglo XIX, para luchar contra la cesantía.

En noviembre de 1909, una Asamblea de ingenieros industriales reivindica un papel más relevante de esta profesión en la tarea de innovación técnica de la industria nacional ${ }^{23}$ con la creación de un cuerpo oficial unificado de ingenieros industriales. Su campaña amenaza a los ingenieros de otras especialidades. En 1911-1912 estalla, por ejemplo, una serie de huelgas de alumnos de las Escuelas de Ingenieros Industriales inquietos por su carrera ${ }^{24}$ cuyos intereses de aspirantes chocaban con los de los ingenieros supernumerarios que solicitaban su reingreso. Estas campañas traducen un malestar frente a una superabundancia de titulados que no encuentran acomodo ni en el Estado ni en las explotaciones privadas $^{25}$. Las profesiones sanitarias y, en particular, los médicos rurales

20 "Mensaje y programa de la Cámara Agricola del Alto Aragón", Reconstitución y Europejsación de España y otros escritos (13 de noviembre de 1989), ed. de Sebastián Martín-Retortillo. Madrid, Instituto de Estudios de Administración Local, 1981, pág. 27.

21 "Quiénes deben gobernar después de la catástrofe nacional" ( 3 de enero de 1900), Ibjdem, pág. 216.

22 Carrasco Canales, C., La burocracia en la España del siglo xix. Madrid 1975, pág. 332.

${ }^{23}$ Asamblea de Ingenieros Industriales celebrada en Madrid, en noviembre de 1909. Madrid 1910.

${ }^{24}$ El Imparcial, 23 de marzo de 1912 y 11 de abril de 1912

${ }^{25} \mathrm{El}$ ministro de Fomento, el liberal Miguel Villanueva, reconocía en 1912 en el Congreso que los nuevos ingenieros formados por el Estado no encontraban trabajo en la Administración. Diario de Sesiones de las Cortes, 29 de mayo de 1912, págs. 173-174. 
se organizan también. A partir de 1911 desde la revista La Sanidad Civil, el doctor José M. ${ }^{a}$ Albiñana Sanz, el futuro fundador del Partido Nacionalista Español ${ }^{26}$, lanza sus primeras campañas.

Sobre este movimiento de funcionarios frustrados o este modelo de sociedad corporativa se fundamentan la mayoría de los proyectos de creación de un partido de intelectuales.

\section{c) Un partido de intelectuales}

Desde Costa hasta Ortega los intelectuales que cuidaron de describir al pueblo en su situación concreta de trabajadores, a la manera de SaintSimon, idearon varios proyectos para organizar a las elites profesionales e intelectuales en un partido.

Desde 1908, Ortega, impresionado por la reciente campaña cívica de Unamuno, pretendía reunirse con él para formar un partido de intelectuales: "Vamos a tener que echarnos, nosotros ideólogos, a la calle. No hay más remedio: es un deber. Hay que formar el partido de la cultura», le escribía. Y le tocaría a este último, poco atraído, en 1914, por el elitismo consustancial a la Liga de Educación Política, reflexionar, diez años más tarde, sobre la oportunidad de contribuir a la constitución de uun partido de la inteligencia» que le proponía Antonio Espina. Ortega en su discurso en el Teatro de la Comedia, en $1914{ }^{27}$ pedía, por fin, la intervención pública de "las minorías que sirvan en ocupaciones intelectuales».

En julio de 1931, Ortega, de nuevo, con su deseo frustrado de convertirse en el intelectual orgánico de una hipotética burguesía, querrá reivindicar, según dice, "un puesto de peligro en la difícil navegación" ${ }^{28}$ y afirmará: “Fiel a mi oficio de ideador, seré siempre sólo un jefe de negociado en el Ministerio de la Verdad» ${ }^{29}$. Aunque gusta de sugerir no sólo que a España "no hace falta que la representen intelectuales", sino también, a la manera de Lenin y de Gramsci, que "el ideal de un pueblo es que no sea necesaria la intervención de intelectuales en su vida política» ${ }^{30}$.

\footnotetext{
26 Vid. Palacios Bañuelos, Luis, Las elecciones en Burgos. 1931-1936. El Partido Nacionalista Español. Madrid 1981, págs. 111-119.

27 Ortega y Gasset, José, "Vieja y nueva política», 23 de marzo de 1914, Obras Completas, Madrid, Alianza Editorial, t.l, 1983, págs. 265-307.

${ }^{28}$ "Las provincias deben rebelarse», OC, $\mathrm{t}$. XI, pág. 356.

29 "En el debate político», Crisol, 31 de julio de 1931; OC, t. XI, pág. 348.

30 Ibidem, pág. 349.
} 
$\mathrm{Si}$, en esta autocrítica, no todo es expresión de aquella "conciencia desgraciada" hegeliana, es cierto que a veces el intelectual se muestra reacio a desempeñar un papel de guía que paternalmente algunos le asignan. «Platón filosaba sobre las espaldas de los esclavos para nosotros esto es estéticamente imposible», apunta, en Juan de Mairena, Antonio Machado que no comparte el elitismo de ciertos discípulos de Giner o de Ortega. Aunque habian esbozado sus teorías y sus doctrinas desde la huelga general revolucionaria de 1917, la mayoría de los intelectuales, que llegaron al poder con la República, no tenían ningún programa preciso. Sólo Ortega y Azaña querían respectivamente racionalizar el funcionamiento del poder y modernizar el Estado. La frustración de esta ambición de transformar la Agrupación al Servicio de la República en un gran partido nacional que una a los "trabajadores de la mente" y a los trabajadores de la mano ${ }^{31}$, según decía, será decisiva en el retraimiento de Ortega, en 1933. Pero se traduce también, paradójicamente, dentro de la burguesía por una reacción de indiferencia o por un antiintelectualismo militante.

\section{ALCANCE, SILOGISMOS DEL ANTIINTELECTUALISMO}

La aparición polémica del «intelectual» suscita en Francia una reacción contraria, irónica o repulsiva de quienes se niegan a otorgar mayor importancia en la sociedad y, sobre todo, en la vida pública a estos profesionales del saber que pretenden intervenir en la política en nombre de la fama que hubieran adquirido en la práctica de su propio oficio ${ }^{32}$.

Ahora bien, encontramos en España una reacción similar frente al nacimiento del «intelectual» español que se autodefine como tal con la firma de manifiestos, a partir del proceso de Montjuich ${ }^{33}$. Evidentemente dicha hostilidad no es nueva, pero se presenta, a partir de ahora, bajo una forma recurrente que nos parece constituir un elemento estructurante de la historia contemporánea de España, que se apodera de todas las clases sociales.

A partir de este momento la actuación o el silencio, las pretensiones - la indiferencia de los intelectuales no dejarán de preocupar a sus coetáneos.

31 Rectificación de la República, op. cit., pág. 414.

32 Y esta molestia la comparten también algunos “dreyfusards" famosos como Péguy, etc.

33 Vid. AUBERT, Paul, "El poder de los intelectuales: manifestaciones y manifiestos", ponencia presentada en el coloquio sobre La vida politica en el Madrid contemporáneo, 1830-1975. Revista Alfoz-Universidad Complutense, 7 de marzo de 1989. 
"¿Qué hacen los intelectuales?, iQué se creen, estos señores, para reivindicar el monopolio de la inteligencia!» Aquella pregunta impaciente e inquieta y esta exclamación airada van a recorrer la historia de España, tanto más cuanto que - por falta de cuadros en los partidos políticos o porque el sistema de la Restauración se muestra incapaz de integrar, como antes, a unos «trabajadores intelectuales" cada día más numerosos- en ningún país europeo, llegaron a tener tanta importancia los «intelectuales". "¿Qué dicen?, ¿qué quieren, los intelectuales?, ¿por qué se callan?».

El antiintelectualismo existe bajo otras formas desde las Luces y se prolonga hasta nuestros días. Para los tradicionalistas españoles, la catástrofe se inicia en el siglo XVIII con el impacto de las Luces, y se prolonga hasta el siglo xx por el intermediario del liberalismo decimonónico. La exposición de sus argumentos es constitutiva de la propaganda falangista y se prolonga hasta la dictadura franquista.

El antiintelectualismo es primero una reacción inmediata de desconfianza frente a la autodefinición de los intelectuales, a su constante y creciente afán de protagonismo político-social. El burgués denuncia el influjo ideológico nefasto del intelectual y su presunta inmoralidad: «El intelectual ha contribuido como pocos a las más disgregadoras doctrinas, pues su modo de tomar el saber (clave de todo) desarticula los principios básicos sobre los que puede asentarse una moral nacional" escribe, por ejemplo, en 1936, Martínez Bande ${ }^{34}$. Al contrario el militante obrero pone en duda la sinceridad de su compromiso: "Siempre he desconfiado de la sinceridad de los "grandes" hombres potentados de "sabios" e "inteligentes" " leemos bajo la pluma de un militante anarquista ${ }^{35}$. Esta molestia inicial puede transformarse en acusación de estafa y de mala fe. "No sé por qué se me antoja que ustedes son unos grandes mixtificadores o unos grandes equivoc ados por eso mismo de creerse "grandes" o "sabios"', leemos en la réplica de un militante anarquista a Unamuno ${ }^{36}$.

No hay pues un antiintelectualismo, sino varios que plantean el problema de las relaciones de estas elites con todas las clases sociales.

En efecto, el antiintelectualismo no es sólo un reflejo conservador, una manifestación de derechas. Además del antiintelectualismo oficial y de las críticas de sus propios colegas, los intelectuales tuvieron que enfrentarse

${ }^{34}$ "El hombre y la verdad", Arriba España. Pamplona, 12 de diciembre de 1936.

35 Al.abuenaga, Benito, "Réplica a Miguel de Unamuno", Tierra y Libertad, 1 de agosto de 1913.

36 Ibidem. 
a un antiintelectualismo proletario y obrerista. Todos dispuestos a evidenciar las razones impuras de sus constantes pretensiones críticas o rectoras.

$\mathrm{Ni}$ la derecha ni la izquierda radicalizadas podian soportar, más allá del militantismo y de las campañas de unos intelectuales, su desmedido e intolerable deseo de opinar sobre todo. Aunque cabe reconocer también que muchos rotativos y revistas desde Alma Española, hasta Nuevo Mundo ${ }^{37}$. España o La Calle, llenaban a veces sus columnas con las respuestas que éstos daban a sus encuestas. $Y$ estas reacciones suscitaban a su vez comentarios y apreciaciones: "Escritores de la categoría de los ilustres han sido invitados por Nuevo Mundo para dar su opinión sobre el "trascendental» problema de Marruecos. $Y$ varios literatos, maestros todos en el arte de escribir, algunos políticos de altura y periodistas afamados, han respondido con la fecundidad de su pluma al deseo del periódico más cortesano de Madrid. Algunas de estas opiniones, como las de Meabe, Martínez Sierra y Ramiro de Maeztu, no están mal: son claras, precisas, lógicas. Otras como las de Unamuno, son laberínticas, excesivamente espiritualistas como él dice» ${ }^{38}$.

De tal manera que, según estas reacciones paralelas, el «intelectual» llegará a ser el chivo expiatorio, el culpable de todos los males que se empeña en denunciar, el constante enemigo del régimen de la Restauración, en suma, propenso a denunciar en nombre de la moral universal las distorsiones evidentes entre las normas morales o jurídicas y su realización políticas. Aunque tanto la Restauración stricto sensu, como la Dictadura cuidaron de encontrar a sus intelectuales orgánicos (algunos krausistas como Segismundo Moret, por ejemplo, o en cierta medida Altamira, o Ramiro de Maeztu, respectivamente).

Este estatuto particular que confieren al intelectual los autores de estos llamamientos ambiguos, más quizá que su radicalización, son objeto de una crítica de índole populista cuyo mejor ejemplo es sin duda a principios de los años veinte la del doctor Ángel Pulido ${ }^{39} \mathrm{y}$, más tarde, la de Ale-

${ }^{37}$ Cf. encuesta de Nuevo Mundo en 1913 (primer trimestre) sobre el problema de Marruecos

${ }^{38}$ ALCORIO, Manuel G., "El problema de Marruecos y el "espiritualismo" de Unamuno", Tierra y Libertad, 30 de julio de 1913, pág. 1.

${ }^{39}$ "Yo renuncio a dirigirme a los intelectuales. El bolchevismo de estos jóvenes que se agitan disolventes en los ateneos, academias, colegios profesionales, redacciones de periódicos, lo encuentro más repugnante que el de los sencillos y engañados obreros, y no merece otro castigo que el que fatalmente ha de reportarles su insensata y ambiciosa locura. Ya deseo sólo hablar a los míos: al puebio, a los humildes, a los extraviados por sugestión, por ignorancia..." (El Cáncer Comunista. Madrid, Núnez Samper, 1921, págs. 19-20). 
jandro Lerroux ${ }^{40}$, quien culpa a los intelectuales del fracaso de la República: «A los auténticos intelectuales, legítimos prestigios del país, procedentes de la cátedra y del foro, se les abrieron los brazos con ese generoso sentimiento de la democracia que parece buscar en la selección de sus mejores la aristocracia natural, legítima, la garantía moral y la dirección y gobierno de la inteligencia para el cumplimiento de su misión. Pero los intelectuales no suelen ser hombres de acción ni se entienden fácilmente entre sí, en tanto que los usurpadores del título son siempre hombres de malas acciones y poco escrupulosos".

Este fenómeno de atración-repulsión que ejercen sobre las clases medias los que detienen el saber, cuando pretenden ser la conciencia de la nación, es coetáneo de la aparición polémica del intelectual, siempre dispuesto a denunciar lo que Francisco Baleriola llama la cpiratería espiritual, ${ }^{41}$, comparando al intelectual con una mujer coquetona que abusa de sus encantos para permitirse opinar y actuar abusivamente "unos y otros sentían con el sexo y con el genio; unos senos perfectos, unos versos bien medidos, una habilidad especial para operar la apendicitis, les daba pretexto para intervenir sin entenderlos, en todos los asuntos y la belleza, el arte o la ciencia sustituian a las razones. (...) Los escritores especialmente al amparo de sus novelas o sus cuentos, lo mangoneaban todo, y singularmente la política, sin la menor competencia, casi siempre poniéndose al lado de la tiranía contra el pueblo" abnegación, apóstol o estafador, piratería, intelectual. Pero el guión que elabora se parece demasiado al anterior para alcanzar una mayor credibilidad" ${ }^{42}$. No obstante esta teoría de la participación que elaboran muchos intelectuales (Zulueta, Albornoz, Machado cada uno a su manera), desde la crisis de los primeros años de este siglo hasta la segunda década para justificar su acción y su pretensión de ser hombres de su tiempo, éstos esbozan, más allá de su crítica de la razón política, una política de la razón crítica (una política de la inteligencia, según decía Valéry).

${ }^{40}$ Lerroux. Alejandro, La pequeña historia de España. 1930-1936. Barcelona, ed. Mitre, 1985, pág 29 .

"1 "Atalaya. Los intelectuales y la política», Nosotros. Madrid, 23 de mayo de 1931, núm. 43, pág. 10.

${ }_{42}$ "Fue necesario que viniéramos nosotros, jóvenes escritores, artistas, hombres de carrera o de estudio, y dejáramos en casa nuestra capacidad y nuestras inclinaciones para nuestros oficios --en los que, entre paréntesis, estábamos destacados-- a implantar normas nuevas, con lo que el dedicarnos, por creerlo un deber, a hacer política, sacrificábamos la gloria y la comodidad para que el pintor famoso que quería hablar del plan quinquenal, por ejemplo, tuviera que documentarse y razonar sus asertos. Y asi por el estilo, sin que le valieran sus laureles" (Ibidem). 
No se puede separar el estudio de los intelectuales del de sus lugares y de sus medios de producción (Madrid, La Tribuna, La Crónica) pero hace falta también considerar su protagonismo en el contexto polémico que presidió a su nacimiento histórico, siendo la mayor polémica la que les reprocha su propia osadía, y su propia existencia.

\section{a) El antiintelectualismo oficial: El poder contra los intelectuales}

En este juego dialéctico entre el saber y el poder, después del fracaso de sus mayores durante la Primera República y el distanciamiento que toman la mayoría de los intelectuales durante el régimen de la Restauración, el antiintelectualismo practicado por el poder alcanza su paroxismo en los momentos críticos.

Más allá del desconocimiento de los intelectuales de parte del monarca -que en vano tratará de suplir Romanones organizando encuentros entre Alfonso XIII y algunos intelectuales, o de las visitas que le hacen aquellos en enero de 1913 (Ramón y Cajal, Cossio y Azcárate) o en 1922 (Unamuno) - sabido es que las relaciones del monarca con los intelectuales no fueron ideales y que el Rey manifestaba a veces cierta indiferencia respecto a algunos de ellos. Aunque no puede afirmarse que el trato que recibió Ortega encontró una respuesta en el famoso «Delenda est Monarquia" ${ }^{43}$, es cierto que la oposición de muchos intelectuales al régimen se explicará por razones casi personales. Más allá de las reacciones pasionales de Unamuno, o Blasco Ibáñez durante la Dictadura -escenografiando su apartamiento desde lo que llamaron la «proscripción»- es evidente que la radicalización de muchos intelectuales y, en particular, la de De los Ríos, llegando a la conclusión de que era imposible hacer funcionar una monarquía constitucional, se fundamenta en una crítica al comportamiento de la Corona.

$Y$ desde el poder, en particular durante la dictadura de Primo de Rivera, se denuncia a los intelectuales por antipatriotas.

La experiencia del Unamuno destituido y tratado despectivamente de «intelectual» por el vicerrector, más tarde desterrado con Jiménez de Asúa,

4.3 "En una ocasión, llevado Ortega y Gasset ante el rey Alfonso XIII, fue presentado por su introductor en esta forma: "Don José Ortega y Gasset, catedrático de Metafísica". A lo que el poco filosófico monarca contestó exclamando con una mezcla de frivolidad borbónica y desfachatez madrileña: "iAtiza!" (ARAQUISTAIN, Luis, El pensamiento español contemporáneo. Buenos Aires, Losada, 1962, pág. 14) 
la de sus compañeros detenidos en 1917 o 1934 (Araquistain, Domingo, Besteiro, De los Ríos, Ovejero, Valle-Inclán, etc.) muestran a las claras que la imagen tópica, desde Larra, del engreimiento o de la melancolía del intelectual perseguido por el poder o en busca de un público, no le aparta ahora en su torre de marfil aunque puede sentir a veces la necesidad de un aislamiento físico o moral.

\section{b) La crítica de sus colegas}

De una manera general, algunos de los que mostraban su disconformidad con la sociedad desde los márgenes de la bohemia (y que trataron luego de organizarse en hermandad en 1913) no apreciaban mucho a los intelectuales. Reivindicaban una rebeldía romántica ${ }^{44}$, luchando genéricamente por "La Verdad, la Belleza y la Libertad" y proponiendo soluciones a problemas sociales o corporatistas que ellos no creían políticos ${ }^{45}$. El romántico Sawa, al contrario, mostró siempre una honda preocupación por la miseria y el retraso social de España y abogó por "una reorganización de la sociedad moderna sobre las bases de moralidad y de responsabilidad cívica» ${ }^{46}$. "Madrid tenía frío y no tenía ideal (...) Los intelectuales eran unos golfos cuarteleros", recuerda Ramón Gómez de la Serna ${ }^{47}$. Mientras el desgraciado trotamundos Eugenio Noël no dejaba de despotricar a lo largo del año 1914 contra "aquellos intelectuales inútiles, los inválidos de las letras" ${ }^{48}$, y otros "parásitos pseudointelectuales" ${ }^{49}$ que no reconocian su labor literaria.

«A chacun son métier»: desde su propio retraimiento algunos escritores indiferentes, amargados o desilusionados por su actuación pasada, negaron a sus colegas el derecho a intervenir en la política en nombre de

44 Vid. BARK, Ernesto, "Por qué soy rebelde», El Radical, 11 de mayo de 1912.

${ }_{45} \mathrm{Tal}$ es el programa de la reunión que convocan para el domingo 30 de marzo de 1913 en el café Mercantil: "Después de cambiar impresiones sobre arte y literatura, con exclusión absoluta de la política, presentarán Juan Alves, Francisco Vega de la Iglesia, Raimundo Díaz, Julio Milego y Urtasus soluciones prácticas para el problema feminista y el del amor, que los bohe. mios tratarán de presentar a las Cortes. El señor Pompey expondrá un plan con el fin de mejorar las condiciones económicas de los pintores, y se leerán trozos de los manuscritos enviados a la Editorial Cooperativa para su publicación, y el señor Bark explicará el funcionamiento de las Oficinas Estadísticas, cuyo objeto es intervenir en la oferta y demanda del trabajo manual e intelectual de hombres y mujeres, y que aspiran los bohemios aclimatar en España, tanto en Madrid, como en provincias" ("Los Bohemios", El Radical, 29 de marzo de 1913).

${ }^{46}$ PhILIPS, Allen, Alejandro Sawa. Mito y realidad. Madrid, Ed. Turner, 1976, pág. 291.

${ }^{47}$ Automoribundia, t. I. Madrid, Guadarrama, 1974, pág. 300.

${ }^{48}$ Diario intimo. Madrid, Taurus, 1968, t. II, pág. 32.

49 Ibidem, págs. 60,69 y passim. 
la moral universal, les negaron este papel, que ellos mismos se habían asignado, de cómitre, de pastor o de guardián del templo para exigir de ellos que se dedicaran seria y exclusivamente a su obra y se olvidaran de un compromiso social que sólo les podía granjear disgustos y dejaran a los periodistas militantes o a sueldo la formulación de la propaganda de partido.

Este antiintelectualismo es, en realidad, un apoliticismo que pretende convencer a los escritores de su error al abandonar o al menoscabar el cultivo de las letras. Enrique Gómez Carrillo, por ejemplo, subraya el carácter lúdico de la política ${ }^{50}$ y suplica, en 1922, a Unamuno que deje de una vez de guerrear «contra esto y aquello» y haga un favor a sus coetáneos traduciendo directamente a los autores griegos cuya obra se lee en España traducida del francés. "Lo grave es que los hombres que tienen que cumplir en el mundo una misión superior de arte, de pensamiento, de cultura, de disciplina espiritual, abandonen el terreno que la Providencia les ha señalado para perderse en los laberintos de un jardín que no produce sino espinas. (...) La única idea a la cual le he sido fiel es la de que un literato, aun Ilamándose Chateabriand o Lamartine, se rebaja al abandonar su arte para consagrarse a la política. (...) Unamunos filósofos, Unamunos ensayistas, Unamunos noveladores, Unamunos helenistas, no hay muchos ni en España ni en el mundo (...) mejor que a redactar «fondos" ingenuamente revolucionarios muy dignos de cualquier diputado de la extrema izquierda; pero indignos de él, debiera consagrarse, ya que tanto preocupa el progreso moral y espiritual de los pueblos españoles, a poner a nuestro alcance la divina sutileza de Platón o la magnificencia patética de Sófocles. Así con todo el fervor de mi cariño, me permito decirle en tono de súplica: Lascia la política».

Gómez de la Serna, olvidando el entusiasmo del compromiso casi familiar de los tiempos de la revista Prometeo y defendiendo su propia posición apolítica, dijo que él no había imitado a aquellos escritores españoles "que quisieron serlo todo", porque creyeron que la publicidad de su pensamiento les otorgaba el privilegio a intervenir constantemente en la vida pública. Llegó a creer al contrario que «se hace la mejor política escribiendo cosas audaces en los libros" y rechazó el puesto de secretario que le ofreció Canalejas ${ }^{51}$ antes de ver confirmados sus prejuicios por lo

50 «Una súplica a Unamuno", $A B C, 15$ de septiembre de 1922. "No es que sus ideas me choquen, no. Yo soy suscriptor de L'Humanité to mismo que lo soy de l'Action Française. Y tanto me entretienen los gritos - retrógrados de León Daudet, cual los clamores comunistas de Cachin. (...) Ahora creo que soy fascista.»

${ }^{51}$ Automoribundia, op. cit t. I, pág. 200. 
que llama «el asesinato político» de su padre, a la sazón diputado, por haberse negado éste a prestarse a una farsa política ${ }^{52}$.

Otros se burlarán asimismo, con una mirada satírica y airada, de aquellos intelectuales «revolucionarios» — «intelectualoides», según la expresión entonces acuñada por Gómez de la Serna- instalados en el poder ${ }^{53} 0$ de los que vinieron indebidamente a pedir favores a la República: "Alrededor de nosotros vemos cómo se premia a gente ambigua, que no ha luchado por la República, ni por nada, topicistas empedernidos. Hombres gordos y sin gracia, ordinaria y antiespiritualmente gordos (...), comilones en restaurantes de lujo, subvencionados secretos de todas las subvenciones, repletos de cartera y con deje de redentores, aparecieron más que nunca en los figones de lujo y presumieron de "forrados"» ${ }^{4}$. Unamuno encontrará también algunas fórmulas contundentes en su artículo titulado «Intelectualismo y deportismo» ${ }^{55}$. A lo cual Machado quien no tenía conciencia ni función de elite opondrá siempre una irónica incomprensión.

\section{c) El antiintelectualismo de derechas}

Una primera forma de criticar la actuación de los intelectuales consiste pues en negar su existencia, en comprobar su ausencia o en criticar su silencio. Una búsqueda tan angustiosa, en suma, como la que viven estos mismos intelectuales en busca del pueblo legitimador de su palabra y de su acción.

"No hay hombres" será el leitmotiv que compartirán con la burguesía a lo largo de la Restauración. Costa justifica así la candidatura de la Unión Republicana, en las elecciones generales de 1903: "Nosotros no venimos en busca de la república por la república precisamente; ni tampoco en

52 "El presidente del Congreso, para que sortease un escollo uno de sus ministros habia pedido a mi padre que no fuese a la Cámara aquella tarde; pero en plena sesión ese ministro que habia motivado su ausencia tuvo la avilantez de señalarla como una claudicación. Al día siguiente mi padre jugándose el todo por el todo, reveló la tramoya y renunció para siempre con voz emocionada a la política y al acta.» (Ibidem, pág. 283)

${ }^{53}$ "La República y sus intelectuales olvidó este mundo que conservaba el ideal, lo olvidó más que nadie, y premió a los intelectuales reborondos, perezosos en butacas inglesas, premiosos de estilo y de investidura, lejanos a la nidada de esos pasajeros de la calle que son líos que podian hacer nacer otro romanticismo literario" (Automoribundia, Op. cit. t. II, pág. 565, 2. ${ }^{a}$ ed.).

${ }_{54}$ Automoribundia, op. cit., t. Il, pág. 566.

${ }^{55}$ La Nación. Buenos Aires, 21 de febrero de 1923 
busca de leyes nuevas ni viejas, en que no tenemos fe ninguna, venimos principalmente en busca de hombres.... ${ }^{56}$.

Aunque los militantes de izquierdas, o los liberales, se empeñen en criticar la propagación de tales tópicos, que Marañón califica de uformas de servilismo disimulado", para demostrar que al contrario estos hombres existen y que "son el vértice de una pirámide formada previamente por la conciencia política de la colectividad" ${ }^{57}$, esta reacción no sólo se explica por un odio genérico al pensamiento, por esencia perturbador. La crítica a los intelectuales pretende denunciar su supuesto antipatriotismo.

Desde los jóvenes mauristas o carlistas, que alborotaban la calle del Prado a la salida del Ateneo, hasta Millán Astray: «Muera la inteligencia, mueran los intelectuales" será el grito de guerra de la extrema derecha, tan frecuente como la irrisión para enjuiciar su labor a lo largo de la República: «Miraron al cielo, posaron en las bibliotecas, cogieron la pluma y redactaron a toda prisa una convocatoria de Cortes Constituyentes, un proyecto de Constitución y un programa de reformas de varias clases, que vino a ponerlo todo patas arriba", escribe Lerroux ${ }^{58}$. Si la derecha suele reprochar a los intelectuales su engreimiento, su pretensión a ostentar el ejercicio del monopolio de la inteligencia, la izquierda les echa en cara su egoísmo y su situación de privilegiados, que se aprovechan de las desigualdades sociales ${ }^{59}$, y éstos no dejan de comprobar su cada vez mayor proletarización, ya sea real ${ }^{60}$ o simbólicamente deseada ${ }^{61}$.

56 Eloy Fernández Clemente, pág. 80.

57 MaRañón, Gregorio, “El tópico de los "hombres"', Nosotros. Madrid, 1 de mayo de 1930, núm. 1, págs. 7-8.

58 La pequeña historia, op. cit., pág. 30

59 "Ellos, que conceden un valor tan grande a su ser, olvidan, egoístamente, criminalmente, que en cada hombre se esconde un valor igual al suyo, humano si no intelectual, y sostienen y defienden a una sociedad que se esfuerza por sostener un privilegio que ellos gozan a costa del dolor, de los sufrimientos y de la muerte de los otros hombres, de la masa del pueblo, del proletariado. (...) Hay que reaccionar contra este intelectualismo hueco y pernicioso; hay que abatir estas grandezas falsas; hay que buscar hombres que to sean, antes que pensadores, antes que ideólogos. Vale más la vida justa, equitativa de la humanidad que todas las fitosofias puras» (MANTEIGA, Luis, “Tonterías. Sinceridad", Nosotros. Madrid, 30 de octubre de 1930, núm. 27).

60 "Colocados en la categoría de la levita, obtenemos menos ganancias, la mayoria de nosotros, que los obreros, y llevamos con esa prenda cargas de varias especies de que se ve libre la blusa. Somos obreros; mas el mundo obrero no ha querido nunca, ni quiere ahora, ni querrá, mientras el socialismo español y la sociología patria sean to que son, reconoceremos como obreros: nos miran como burgueses, con todas las prevenciones que a éstos, y los burgueses nos tratan peor que a los obreros. Estamos, como el alma de Garibay, entre el cielo y la tierra, sin ser de uno ni de otro." (Ferrándiz, J., "Cosas de la prensa. Condición del periodista", El Radical, 4 de enero de 1912).

61 «Hoy abogados, maestros, ingenieros, etc., son y no quieren ser otra cosa que proletarios" ("Proletarios e intelectuales", art. cit.). 


\section{d) El antiintelectualismo de izquierdas}

Ahora bien, la adhesión razonada al partido del proletariado, a partir del momento en que el PSOE matiza su línea obrerista para acoger a algunos intelectuales a partir de 1912, no basta para proletarizar al intelectual.

Los órganos militantes hablan duramente de los intelectuales aunque no rehusan el debate ni les cierran sus columnas. Encontramos, por ejemplo, las firmas de Unamuno y Araquistain, de Albornoz, Maeztu, Baroja, y Zulueta, incluso en los tiempos difíciles del obrerismo estricto, respectivamente en La lucha de clases y El Socialismo, en La Aurora Social y Tierra y Libertad.

De hecho esta reacción es de dos tipos. Se condena primero el retraimiento de los artistas en general en una torre de marfil, y se pone en duda la función social de unos "señoritos que matan sus ocios manchando cuadros o pergeñando versitos (...) emancipados de toda carrera útil por el dinero de papá» ${ }^{62}$ (que algunos llegarán casual y coyunturalmente a reivindicar).

Baroja explica que se odie a los artistas porque "gozan del privilegio de vivir sin trabajar (de aquí su criterio reaccionario en política)» ${ }^{63}$. Lo cual viene a recalcar la ambigüedad de las relaciones del intelectual con lo que se llama genéricamente el pueblo. Ir hacia el pueblo presupone que se viene de otro lugar. De hecho los intelectuales son percibidos y descritos como unos seres que "pretextando la posesión de una superioridad mental se constituyen en minoría aparte, titulándose pomposamente "minorías inteligentes", lo cual no es la mejor manera de lograr la igualdad social» ${ }^{64}$ y sólo merecen "una sonrisa compasiva" de parte de los periodistas de la clase obrera.

Leemos este retrato caricaturesco en Tierra y Libertad: «No es posible formarse una idea completa de un intelectual moderno sin tener en cuenta lo que le caracteriza y distingue de la masa: los oportunos lentes, luengas melenas y un inmenso bagaje de frases sonoras" ${ }^{65}$. $Y$ el periodista se burla de lo que llama «la fiebre de intelectualismo que padecen la mayoría

${ }^{62}$ Lozano, Luis, "El señoritismo en acción. Avanzados en arte; en política, retardatarios", Nosotros. Madrid, 20 de noviembre de 1930, núm. 30.

63 Ibidem.

${ }^{64}$ Fructidor, Federico, "Los intelectuales», Tierra y Libertad. Barcelona, 25 de enero de 1911, pág. 1.

65 Ibidem. 
de aspirantes a superhombres, pretendiendo subordinar a su voluntad las innumerables fuerzas proletarias que luchan para fines más prácticos y elevados".

Los anarquistas, en realidad, dudan entonces de la necesidad de estos "llamados intelectuales" que se valen egoístamente de su saber en las luchas entre el capital y el trabajo asegurando que «el pueblo irá abriéndose camino por sus propias fuerzas". Llegan incluso mucho más lejos "esas inteligencias superiores, vienen a ser como una especie de filoxera ocupada en destruir el viñedo de las grandes ideas sociales». Tierra $y$ Libertad matizará sin embargo esta postura al comentar, bajo la pluma de Eduardo G. Gilimón, la famosa conferencia que dio Ramiro de Maeztu en el Teatro Principal de Barcelona el 5 de marzo de 1911 y en la que se quejaba, desde un enfoque fabiano, de que en España los intelectuales siguieran apartados del socialismo ${ }^{66}$. De hecho Gilimón niega a los intelectuales cualquier capacidad para eregirse en clase rectora de la sociedad aunque sí reconoce que «en cambio hacen falta (los intelectuales) para ilustrar a los obreros» ${ }^{67}$.

Tras la publicación por Ortega del manifiesto de la Liga de Educación Política y su famoso discurso del Teatro de la Comedia, El Socialista manifiesta su decepción frente a la postura reformista y a la irresolución del filósofo: «El partido socialista, en España como en China, a pesar de las corrientes revisionistas, es un partido de clase; y no hay más. Se está con la clase obrera o se está con la clase burguesa» ${ }^{68}$. Este malestar se transforma rápidamente en hostilidad manifiesta: «Realmente, nosotros, no hemos sufrido una decepción más porque nada esperábamos de él, como nada esperábamos de los de su casta. No borramos la frase: los de su casta. La casta intelectual española es incapaz de nada generoso, su corazón no late al unísono con el del pueblo porque no tiene corazón", acusa Andrés Saborit ${ }^{69}$, quien tanto admiró sin embargo a Julián Besteiro, el filósofo neokantiano que era a la sazón líder del sindicato socialista.

Sea por su impaciencia en denunciar la apatía del pueblo víctima del caciquismo, sea por el idealismo de las soluciones que propone -como le reprocha el cronista de El Socialista a Ortega, después de la publicación de sus artículos en El Sol, en 1927- se acusa genérica o individualmente

\footnotetext{
${ }^{66}$ "Obreros e intelectuales", en MAEZTU, R. de, Liberalismo y socialismo, ed. de Inman Fox. Madrid, Centro de Estudios Constitucionales, 1984, págs. 86-113.

67 GiLIMón, Eduardo G., «Intelectuales y obreros», Tierra y Libertad, 22 de marzo de 1911, pág. 2.

${ }^{68}$ El Socialista, 19 de octubre de 1913.

"O9 "Ortega y Gasset, monárquico", Acción Socialista, 28 de marzo de 1914, pág. 3.
} 
a los intelectuales de egoístas ${ }^{70}$ e hipócritas o más suavemente se les reprocha su desconocimiento de la realidad: "No es que el pueblo no quisiese votar, es que no le dejamos votar libremente. No es que no le interesase al pueblo la vida pública; es que le prohibían intervenir en ella. Conocemos a muchos hombres que no saben escribir tan bien como Ortega y Gasset, pero que seguramente tienen más conciencia de lo que es la política que él, que se han jugado muchas veces su pan y el de su familia en defensa del derecho electoral. Si esos artículos estuviesen escritos especialmente para matar el optimismo del pueblo, que anhela su redención, y para servir a la reacción, no le saldrían mejor al señor Ortega y Gasset. $Y$ luego blasonan de liberales estos intelectuales. De liberales y radicales. Cuantos campesinos, de esos que (sic) el señor Ortega y Gasset niega capacidad para votar, se reirán al leer sus artículos» ${ }^{71}$.

Pero, más allá de esta acusación de fatuidad, de parasitismo o de incomprensión de las masas populares, de sus organizaciones sindicales ${ }^{72}$ y de sus medios de lucha que hacen los militantes a los que llaman «intelectuales de cartel" (Maeztu considera que la huelga general es un mito y trata de probar que el sindicalismo revolucionario es cantiintelectual y antiinteligente», cuando los órganos obreros repiten que la buena voluntad de los intelectuales es inútil "mientras perdure el sistema actual» ${ }^{73}$ ), se perfila otra crítica, la de una izquierda radicalizada que les reprocha su frivolidad, su claudicación o su inconsecuencia, pasando a servir como "verdaderos intelectuales a sueldo" " "mercenarios apologistas de un código atávico y una tradición absurda" (no se decía todavía orgánicos) el régimen y la clase social que habian combatido. De este transfuguismo, esta traición que se reprocha a la sazón a Azorín, Claudio Frollo o Julio Camba, serán también protagonistas, a lo largo del primer tercio de este siglo varios de ellos, siendo el caso más famoso el de

70 "Conocemos a fondo esos maquiavelismos; es el titánico esfuerzo de los titulados intelectuales. Educados en un ambiente de hipocresía, nutridos solamente de preocupaciones, no tienen la fuerza de convicción necesaria para despojarse de su bajo orgullo y poner sus conocimientos, si de tales puede llamarse el bagaje de eruditismo que padecen, al servicio de los desheredados, de los humildes, desarrollándoles su inteligencia, haciendo de ellos hombres fuertes y conscientes y elevándoles al debido nivel intelectual para que puedan lograr de común acuerdo la participación en el patrimonio universal a que tienen perfecto derecho" (lbidem).

${ }^{71}$ "La realidad que descubre Ortega y Gasset», El Socialista, 27 de enero de 1928, pág. 4.

12 Por ejemplo, "un sindicalista" anónimo reprocha a Maeztu su "desconocimiento completo de la actual organización separada de la política, que ya en todo el mundo se conoce bajo el nombre de sindicalismo" ( Un intelectual equivocado", Tierra y Libertad, 10 de abril de 1912).

73 Alabuenaga, Benito, "Intelectuales e inteligentes", Tierra y Libertad, 11 de julio de 1912.

${ }^{74}$ SoleR, L., «Actuación socialista. Intelectuales a sueldo". Tierra y Libertad, 20 de marzo de 1912, pág. 2. 
Maeztu, pero se puede citar los nombres de Pérez Solís, etc.; nómina que se alargaría sobremanera si llegáramos al verano del 36 , aunque esto es indudablemente otra historia a la que aludiré sólo a título de epilogo.

Otro motivo de incomprensión de los intelectuales es su supuesta cobardía, al no atreverse a destruir el orden antiguo y se reprocha, por ejemplo, a "un grupo destacado de intelectuales, hombres de arte y de ciencia, hombres cumbres, pertenecientes, por cierto, a una "manera" que se está pasando (...) "parvenus" de la República ante el pueblo" de favorecer la elaboración de una Constitución supuestamente reaccionaria $^{75}$. Y el mismo autor exclama en otro artículo: “iCuán justificado está el desprecio de los comunistas por los intelectuales! ${ }^{76}$.

Rechazado por la burguesía como traidor a su clase y por altruismo excesivo y por su calidad de burgués egoista por el proletariado, el intelectual llega a ser un personaje molesto que tiene problemas de ubicación y, por consiguiente, de identidad.

\section{LIMITES DEL ELITISMO Y RADICALIZACIÓN FINAL}

a) Los intelectuales son víctimas de una tradición elitista

Los intelectuales alcanzaron tanta importancia durante el régimen de la Restauración que llegaron brevemente a serlo todo. No sólo dispusieron del poder de la palabra, hasta el punto de arrebatarle al poder el monopolio del discurso social, sino que llegaron a ser el símbolo mismo, la voz y la palabra del nuevo poder que se instauró el 14 de abril de 1931 y que el «maestro» Azorín, cachorro ciervista, favorable a la dictadura de Primo de Rivera luego, y recientemente convertido al republicanismo, gran acuñador de expresiones históricas, no dudaría en llamar: "la República de los intelectuales." Pasada la euforia del triunfo que provoca la peligrosa constitución de un discurso referencial, e incluso tautológico, cuando hace falta a la vez definir y hacer funcionar un nuevo régimen, los intelectuales recobrarán su independencia y su función crítica hasta el punto de expresar sus amarguras y sus ilusiones tras el fracaso de la experiencia reformista en España.

75 BALeriola, Francisco, “Atalaya. Los intelectuales y la política», Nosotros. Madrid, 23 de mayo de 1931, núm. 43.

"Baleriola, Francisco, «Atalaya. Pro frente único revolucionario», Nosotros. Madrid, 1 de agosto de 1931, núm. 53. 
Si no habian conseguido la "rectificación de la República» que tanto deseaban, algunos, más desilusionados, como Ortega y Unamuno, habían empezado a rectificar, a lo largo de estas semanas, su propia interpretación del 14 de abril de 1931, relativizando el alcance del cambio de régimen y minimizando la importancia de su propio papel en el advenimiento de la República, mediante un distanciamiento fisiológico o histórico. Al "aldabonazo» de Ortega, que se había convertido en deseo de rectificar a la República desde septiembre de 1931, hacía eco la cuádruple negación unamuniana de septiembre de 1933 para exigir la revisión de la Constitución. Ambos opondrian a las circunstancias un reflejo liberal y supeditarían las incertidumbres del realismo y del compromiso político a la nitidez de la política de la inteligencia y de la voluntad.

Los mismos hombres que habían elaborado y votarían la Constitución empezaron a pedir su reforma. A los pocos meses encontramos el diagnóstico definitivo de Unamuno: «Una Constitución tramada por intereses de partidos..." "7. El de Ortega no tardaría: "Constitución lamentable sin pies ni cabeza" ${ }^{78}$. La condena es rotunda. Difícilmente encontraremos fuera de los escritos de Azaña, de De los Ríos o de algunos radicales socialistas, cualquier proyección positiva del nuevo texto constitucional. Hasta Jiménez de Asúa, el presidente de la comisión redactora expresaría sus reticencias y calificaría con amargura su propia labor: "Tiempo perdido aquello" ${ }^{79}$.

Estos intelectuales se encuentran, por consiguiente, de nuevo opuestos al poder, evidenciando el desajuste que existe entre sus propios valores e ideales proclamados y la realización jurídica de éstos. De nuevo su discurso tiende hacia lo universal, cuando se mueven en la particularidad de una coyuntura crítica.

En 1933, algunos de ellos están desilusionados o amargados por el rumbo imprevisto que ha tomado, frente a la radicalización de los conflictos sociales, aquella República que habían deseado desde principios de los años veinte y que habían contribuido a instaurar dos años antes, llegando a ser miembros destacados de su poder constituyente, legislativo o ejecutivo.

Los intelectuales, que pasaron de buen grado por la encarnación de la República, se habían transformado, conforme iba avanzando la obra constituyente, y se verificaban los primeros actos de gobierno, en sus

${ }_{77}$ La Voz, 24 de octubre de 1931.

${ }^{78}$ Luz, 16 de julio de 1932.

${ }^{9}$ Jiménez de Asúa, Luis, Anécdotas de las Constituyentes. Buenos Aires, 1941, pág. 33. 
fiscales más severos, hasta el punto de considerar que el texto que estaban redactando había llegado a constituir un peligro para España.

Si a lo largo de la Restauración y de la Dictadura los intelectuales llegaron a constituir, por la constancia de su protesta frente al bloque de poder, un verdadero grupo de presión ideológico, durante la República llenaron tan sólo un vacío político supliendo la ausencia de cuadros de los partidos republicanos y socialistas, y perdieron, la relativa homogeneidad que se habian forjado en su lucha contra la monarquía, preocupados por la única tarea de traer la República a España.

Encontraron esencialmente dos tipos de dificultades. Por una parte, estos momentos de gran febrilidad política y de inflación verbal eran propicios al análisis de las estructuras pero no todavía al de las funciones del nuevo poder, y postulaban sobre todo la necesidad del abandono de un discurso crítico paralelo o ajeno al del poder. No se podía ser a la vez el poder y la crítica de este poder. $Y$ era difícil abandonar esta función fiscalizadora adquirida o perfeccionada en la lucha contra el régimen de Primo de Rivera. Por otra parte, la incipiente dialéctica de la ambición funcionalista - para quien, como Azaña, hacía falta "cambiar el sistema político y la política del sistema - chocaría, en un momento de creciente disgregación de los partidos mayoritarios y de nueva agregación de intereses económicos, contra los círculos agrarios, las asambleas católicas y los grupos patronales, es decir, contra otras elites que no habían perdido el poder económico y volvieron a recuperar el aparato del Estado con el segundo bienio - llamado a veces curiosamente por los historiadores «bienio rectificador", como si la historiografía tuviera por misión, como la política, rectificar el pasado, ponerlo derecho, según lo proponía el apócrifo de Machado, Juan de Mairena.

En buena medida pues los intelectuales son víctimas de una tradición elitista descuartizada entre la incultura y la reacción pero lo son también de sus propias ilusiones.

\section{b) Los intelectuales son víctimas de su propio discurso}

Si no se podía transformar el mundo social cambiando, como antes, el conocimiento que de él se tenía, tampoco era posible hacerlo modificando tan sólo su representación ideológica o política (parlamentaria), en un momento de creciente agudización de los problemas sociales, nueva versión aquélla de la desilusión finisecular formulada por Costa: "La Ijbertad se había hecho papel pero no se había hecho carne".

El consabido dilema entre la reforma y la revolución se estaba transformando bajo el peso de las circunstancias, en alternativa entre revolu- 
ción y contrarrevolución, que provocaba el retraimiento de unos y la radicalización de otros.

Poco importaria entonces la confusión inicial de las situaciones y de las actitudes; era demasiado tarde para seguir reflexionando sobre la esencia y los fundamentos de un poder que hacia falta ejercer al mismo tiempo. Quizá la disolución de la Agrupación al Servicio de la República, el 13 de octubre de 1933, reduciendo la interpretación de su papel a la lucha pretérita por el advenimiento de la República y la convocatoria de unas Cortes Constituyentes, simbolice aquella desilusión de unos intelectuales bien intencionados frente a la realidad política, que volverían con sus artículos y sus conferencias a dirigirse a la opinión pública, pero abandonarían cualquier responsabilidad política. La difícil postura de Fernando de los Ríos (el intelectual que sin duda incarne mejor el período en las Cortes Constituyentes y, con la excepción de Azaña, el primer bienio), incapaz de dudar de la validez de la vía democrática que habia preconizado para llegar al socialismo y deseoso de estar al lado de sus compañeros frente al drama que presiente tras la ruptura de la conjunción y la radicalización del PSOE, representa, con la súbita y efímera metamorfosis de Araquistain en teórico revolucionario, el fin del intelectual tradicional que firma manifiestos o redacta leyes. $Y$ confirma, sobre todo, la difícil adecuación del discurso ideológico de los intelectuales a una realidad que estaban convencidos de haber creado, pensando tener una vocación prioritaria para describirla e interpretarla. (Lo cual viene a recordarnos que no hay realidad objetiva, hechos o sucesos brutos no mediatizados).

Lo que muchos ilustrarían con una huida, elegante o no a partir del verano del 36, frente a unos acontecimientos que les impedian tomar partido. Esto no significa que tanto la República en guerra como el régimen de Burgos no tuvieron sus intelectuales. Pero es otra historia.

Al querer identificarse con el nuevo régimen, los intelectuales tenian que responsabilizarse tanto de los éxitos de éste como de sus fracasos. Y cabe preguntarse si esta "República de los intelectuales" no fue víctima de los límites de un discurso que pretendía haberla constituido pero tenía dificultades para definirla, y no bastaba para hacerla funcionar.

Luego los intelectuales se fueron física o moralmente. El autor del himno de la República, Manuel Machado, en quien Azorín, que habia acuñado la expresión "República de los intelectuales», veía "el maestro de los escritores nacionales", dedicó odas al general Franco. Mientras tanto, Unamuno afirmaba desesperado a Nikos Kazantzakis que la nueva ge- 
neración se caracterizaba por su odio al espíritu ${ }^{80}$.Triste epílogo aquél. Gómez de la Serna tuvo que arreglar y fortificar un poco su torre de marfil. Confesó haber puesto «unos colchones en las ventanas de (su) alcoba», haber colocado «la librería del diccionario enciclopédico trente a la puerta, porque no sabía quién podía venirme a matar, aunque yo no intrigué nunca, ni conspiré, ni usé del toma y daca, pues sólo estuve abstraído en mis cosas para ver si podía dar a mis contemporáneos una visión más exacta de la vida y de la ilusión, que fuese original' ${ }^{81}$. Porque no podía soportar escribir en agosto del 36 con las ventanas cerradas, decidió marcharse a América desde Burdeos con el pretexto de asistir al Congreso de los PEN Club en Buenos Aires ${ }^{82}$. Gregorio Marañón, Ramón Pérez de Ayala, Claudio Sánchez Albornoz, Eduardo Ortega y Gasset, Luis Buñuel, Carlos Arniches, se valieron de estratagemas parecidas. Salvador de Madariaga, también ${ }^{83}$, antes de intentar vanamente interceder entre ambos contendientes sin lograr el apoyo de las potencias europeas ${ }^{24}$.

Manuel Azaña se apiadará de ellos con su ironía feroz: «Republicanos para ser ministros y embajadores en tiempos de paz. Republicanos para emigrar en tiempos de guerra", dirá a propósito de Claudio Sánchez Albornoz a punto de marcharse para dar un curso en la Universidad de Burdeos. El antiintelectualismo tenía pues un gran porvenir tanto entre los partidarios de la insurrección franquista como el profesor Suñer ${ }^{85}$, que culparía a los intelectuales de todos los males de la patria, como entre los defensores de aquella Tercera República nacida de las urnas del Frente Popular.

Contribuir a la formación de un hombre nuevo, a la creación de una

B० Du Mont Sinaï à lîle de Vénus. Carnets de voyage. París, Plon, 1958, pág. 154.

a) Automoribundia, op. cit., t. II, pág. 610 .

82 “Como fundador con Azorín del PEN Club en Madrid, mi estratagema fue pedir un pasaporte para asistir al Congreso de los PEN Club que se celebraba en Buenos Aires. Lo conseguí y la víspera de marcharme, al pasar frente a la terraza de la Granja del Henar — frente al palacio de Bellas Artes donde había de estar la Checa--, con una imprudencia trágica grité a la tertulia de los poetas: "De aquí hay que marcharse... Yo me voy mañana"» (Automoribunda, op. cit., t. II, pág. 611).

83 Madariaga, Salvador de, Memorias (1921-1936). Amanecer sin mediodia. Madrid, EspasaCalpe, 1974, págs. 562-563.

${ }^{84}$ Garcia QuiePo de Llano, Genoveva, «El fracaso de Madariaga. Intentos mediadores en la Guerra Civil española", Historia 16, núm. 116, págs. 11-19.

as SUÑER, Enrique, Los intelectuales y la tragedia española, s.I., Editorial española, 1938, 172 págs. 
opinión pública, regenerar o vertebrar el país, forjar la unidad nacional, emancipar al proletariado, contribuir al advenimiento de la república: la diversidad de los fines que los intelectuales asignaban a su palabra y a su acción difícilmente podía vencer las paradojas de la vida política española y la ambigüedad sobre la que se fundamentaba el régimen de la Restauración. Aquella burguesía hostil a los intelectuales no dejaba de proclamar que el país necesitaba hombres nuevos. Gustaba de criticar las formas democráticas de gobierno cuyo verdadero funcionamiento ignoraba, al mismo tiempo que se lamentaba por la incultura nacional, sin dejar de denunciar el carácter subversivo de las iniciativas pedagógicas o políticas de los hombres cultos. Por otra parte, estos mismos obreros socialistas, que dudaban de la sensibilidad de los intelectuales, se habian dotado de un líder que era un filósofo neo-kantiano. Pero cualquier intento de explicación de este antiintelectualismo parece sospechoso, sobre todo cuando procede de un intelectual: «¿Por qué este odio al intelectual? Probablemente porque el español medio ve en el intelectual la personificación de lo que más odia: la preocupación de someter a disciplina su espíritu» ${ }^{86}$.

Estas reacciones paradójicas contra el parlamentarismo y el intelectualismo en un país minado por el caciquismo y el analfabetismo expresan sin duda las contradicciones de una burguesía que no logra adaptar sus costumbres políticas a las exigencias de la democracia en un momento, es cirto, en que el sistema parlamentario experimenta una honda crisis en toda Europa y en que se vive en España una evidente polarización político-cultural en torno a la revolución y a la contrarrevolución. Esta impresión de vivir una crisis generalizada de los valores imposibilita la superación del malestar crónico del intelectual tradicional: "Vivimos en una época de transición y de fluencia. En rincón ninguno de la tierra hallaremos unidad ideológica y sentimental»" ${ }^{87}$, advertía Pérez de Ayala, en 1927, planteando proféticamente la cuestión de la identidad, de la ubicación y del papel del intelectual en la crisis de la sociedad burguesa.

¿Qué son los intelectuales en España? ¿Qué son ante el cambio, ante la Restauración, ante la Dictadura, ante la República? - para atenernos a la temática de este congreso-, pues lo son todo. Son el cambio, son la República. Al menos tales son sus pretensiones. Son quienes escriben la Historia. Consiguen cambiar, si no la historia, siquiera la percepción que

\footnotetext{
${ }^{86}$ Pérez Bances, J., “El odio al intelectual», España, 25 de noviembre de 1922, núm. 345, pág. 4.

${ }^{87}$ "Público, pueblo y plebe”, El Sol, 24 de noviembre de 1927
} 
de ella se tiene. Logran contar al pueblo su propia historia -epopeya y utopía confundidas-. Es decir lo que les gustaría que fuera o que éste creyera que fue. Indudablemente la autodefinición inicial suponía la autocrítica y el sufrimiento en este afán elitista o humanista de conseguir, si no una historia inteligente, al menos de vivir una historia inteligible, de alcanzar "la inteligibilidad de la Historia». 